\title{
EDITORIAL
}

\section{Irrational responses to COVID-19}

Driven by ignorance and fear, ancient man attributed natural phenomena such as the movement of celestial objects, eclipses, thunder and lightning, storms, floods and drought, to the whims of unseen supernatural beings and forces.

The realisation that there was a pattern in the occurrence of natural phenomena led to the slow development of the search for antecedents to occurrences and to the concept of cause and effect, and the view that there were discoverable impersonal laws that govern the world we live in. This view has now become an integral part of the thought processes of modern man, being both the driving force and the result of the flowering of science that began in the $17^{\text {th }}$ century which then developed alongside science-based technology, right through the $20^{\text {th }}$ century.

It is evident and understandable that in the face of a pandemic, sections of society will turn to occultism/ religion for succor. This is particularly true in traditional societies such as Sri Lanka, where the scientific temper of mind is not widespread. From an evolutionary view point, the brains of human beings are wired in such a way as to give 'intent' to inanimate objects and natural phenomena. The irrational enthusiasm of the public for various untested concoctions of unspecified composition which are claimed to be effective against COVID-19, promoted by various individuals and media organisations can only be understood in this context.

Modern science has developed highly sophisticated methodologies for judging the efficacy and safety of medicines for human usage. It is heartening to note that the authorities are officially on the side of Science (evidence-based medicine) and not Irrationality.

The high public interest in the current widely publicised irrational cures makes it an opportune time for scientific and medical professional organisations to undertake the education of the general public on the rationale for the scientific methods used in evaluating the efficacy and safety of medicines for human usage.

Ajit Abeysekera 